\title{
Sobre la aplicación del Estatuto Básico del Empleado Público a los Cuerpos de Policía Local y el principio de especialidad normativa consagrado en la Ley 0 rgánica de Cuerpos y Fuerzas de Seguridad. Sentencia del Tribunal Superior de Justicia de Andalucía, de 4 de mayo de 2010
}

\author{
Jaime H ernández Vaillo \\ Letrado de la Junta de Andalucía
}

\section{INTRODUGCIÓN}

El presente comentario tiene por objeto la Sentencia de 4 de mayo de 2010, dictada en Apelación $n^{\circ}$ 60/2010, por la Sala de lo contencioso-administrativo del Tribunal Superior de Justicia de Andalucía, Sede de Sevilla.

En una primera aproximación al texto de la Sentencia, parece que el tema se circunscribe a la mera fijación o no de un límite de edad en el acceso a los Cuerpos de Policía Local. No obstante, en una lectura más profunda descubrimos que el interés de su contenido se halla en la aplicación o no del régimen especial de las Fuerzas y Cuerpos de Seguridad del Estado frente al régimen general estatutario del Estatuto Básico del empleado público.

Resulta así, que los Cuerpos de Policía Local se regulan en la Ley Orgánica 2/1986, de 13 de marzo, de Cuerpos y Fuerzas de Seguridad (en adelante LOCFS), que otorga a las Comunidades Autónomas la competencia para fijar los criterios de selección, entre los que se incluye el de la edad, sin especificar el rango normativo.

No obstante, tras la entrada en vigor de la Ley 7/2007, de 12 de abril, del Estatuto Básico del Empleado Público (en adelante EBEP), se plantea si su artículo 56, que exige reserva de Ley para la fijación de un límite de edad distin- 
to al de jubilación forzosa, debe ser de aplicación preferente a la LOCFS, o si ésta debe prevalecer en virtud del principio de especialidad. En caso contrario, la edad de acceso no podría determinarse en disposiciones de carácter general, sino exclusivamente mediante Ley, lo que conllevaría la ineficacia sobrevenida de las normas reglamentarias que se hubieran dictado en su desarrollo por las Comunidades Autónomas.

\section{RESUMEN:}

En el Recurso contencioso-administrativo, seguido por los trámites del procedimiento abreviado, se impugnaba la Resolución de 24 de julio de 2008 del Ayuntamiento de Sevilla, que aprobaba las bases generales correspondientes al proceso selectivo para cubrir plazas de policía local en la ciudad de Sevilla.

El Recurso fue interpuesto por uno de los aspirantes a la citada convocatoria, alegando que la previsión por las bases de una edad límite de 35 años para el acceso al Cuerpo, resultaba supuestamente discriminatoria y carente de racionalidad, con la consiguiente vulneración de los artículos 14 y 23.3 de la Constitución, sin que exista una hipotética mayor capacidad para el desempeño de las funciones del Cuerpo por el hecho de superar un límite de edad, circunstancia que ya quedaba satisfecha por la realización de las pruebas físicas pertinentes.

Por su parte, la Administración de la Junta de Andalucía basó su defensa en la plena y estricta aplicación por las bases de lo dispuesto en el artículo 18 del Decreto 201/2003, de 8 de julio, de ingreso, promoción interna, movilidad, y formación de los funcionarios de los Cuerpos de Policía Local (en adelante Decreto 201/2003), que concreta ese límite de edad, estando vinculada la Corporación Local por la prohibición de la derogación singular de los reglamentos.

El Ayuntamiento de Sevilla articuló similares alegaciones oponiéndose al Recurso, y añadiendo que las funciones y características especiales de estos Cuerpos imponen un tratamiento diferenciado respecto a otros, y que suprimir el límite de edad implicaría un progresivo "envejecimiento" del Cuerpo, en perjuicio de la prestación del servicio público.

Sin embargo, la Sentencia del Juzgado de lo Contencioso-Administrativo $\mathrm{n}^{\circ} 9$ de Sevilla, de 28 de julio de 2009, consideró que el Decreto 
201/2003 habría devenido inaplicable de forma sobrevenida como consecuencia de lo dispuesto en el artículo 56 EBEP, según el cual sólo podrá establecerse una edad de acceso a la función pública distinta de la edad de jubilación, mediante Ley.

Asimismo, razona que el límite de edad para el acceso al Cuerpo de Policía Local, fijado en 35 años, no se encontraría suficientemente motivado por las bases de la convocatoria, anulando dicha previsión y estimando, en consecuencia, el Recurso.

\section{RAZONAMIENTOS Y DOGTRINA QUE CONTIENE LA SEN- TENGIA}

Frente a dicha Sentencia del Juzgado, se interpuso recurso de apelación por Administración de la Junta de Andalucía, fundada en la inaplicación de la reserva de Ley del artículo 56 EBEP, norma que excluye expresamente de su ámbito a los Cuerpos y Fuerzas de Seguridad en general, y a los Cuerpos de Policía Local en particular; y la plena aplicación de la LOCFS, que en su artículo 39 otorga a las Comunidades Autónomas la competencia para fijar los criterios de selección, sin que nada se especifique respecto al rango normativo que deben ostentar estas previsiones, en este caso contenidas en el Decreto 201/2003.

La parte apelada se opuso a dichas manifestaciones, alegando que EBEP sería aplicable a título supletorio, sin que la LOCFS habilite a las Comunidades Autónomas para dictar normas con rango reglamentario, y que el establecimiento de un límite de edad tendría carácter discriminatorio, defendiendo la plenitud de facultades de personas con edades avanzadas para el acceso al Cuerpo, y el paso a segunda actividad, así como que en todo caso el límite de 35 años sería desproporcionado.

La Sentencia de la Sala aquí comentada, rechaza el Recurso de apelación interpuesto, confirmando el fallo dictado en la instancia, por cuanto la LOCFS nada contemplaría respecto a la determinación del requisito de la edad, sino que "el artículo 39 se limita a otorgar a las Comunidades Autónomas la coordinación de la actuación de las Policías Locales en el ámbito territorial de la Comunidad, entre otras funciones las relativas a fijar los criterios de selección, formación, promoción y movilidad de las Policías Locales", sin que exista "precepto legal alguno que exceptúe la aplicación del artículo 56.1.c) EBEP, en cuanto exige norma con rango de Ley para establecer la edad máxima de acceso al empleo público". 
Tras analizar la doctrina del Tribunal Constitucional, la Sentencia concluye también que las bases son discriminatorias, pues no han "justificado la fijación de la edad máxima en 35 años" y "tampoco se determinan los perjuicios que una mayor edad de acceso suponen para la organización del servicio".

\section{GOMENTARIO}

A nuestro modesto juicio, consideramos que la interpretación a la que llega la Sentencia, que supone inaplicar una norma reglamentaria, podría ser gravemente dañosa para el interés general.

Dicho quebranto se manifiesta en la preterición del régimen jurídico de la LOCFS por superposición del EBEP, en este caso concreto con relación al requisito de la edad, pero que puede extrapolarse a otras cuestiones reguladas en LOCFS, lo que supondría la aplicación del EBEP sobre una norma de carácter especial, en cuanto al régimen de los Cuerpos y Fuerzas de Seguridad del Estado.

Igualmente, se produciría un grave daño al servicio público, por cuanto interesa a los ciudadanos que los integrantes de los Cuerpos de Seguridad posean una capacidad y aptitud física adecuada a las funciones que desempeñan. Está en juego, pues, la seguridad pública, por lo que resulta esencial que los miembros de las Policías Locales reúnan las condiciones necesarias que dicho Cuerpo exige para la prestación del servicio con las máximas garantías.

Por ello, la inaplicación de una norma reglamentaria, concretamente el artículo 18 del Decreto 201/2003, dictada en desarrollo de la competencia que atribuye el artículo 39 LOCFS, supone no sólo la preterición del régimen especial de la LOFGS, sino también que no exista límite de edad para el acceso al Guerpo de Policías Locales, por lo que cualquier persona puede participar en los procesos de selección, y ser adjudicataria de una plaza, independientemente de su edad, lo que desde luego repercute de forma directa en la prestación y calidad del servicio público.

El artículo 104.2 de la Constitución establece que "Una Ley Orgánica determinará las funciones, principios básicos de actuación y estatutos de los Cuerpos y Fuerzas de Seguridad". Es decir, la LOFCS contiene una regulación 
propia de este colectivo de funcionarios, que cuentan con una serie de importantes peculiaridades y limitaciones en su régimen jurídico.

Entre los cuerpos que integran las Fuerzas y Cuerpos de Seguridad del Estado, están sin duda los Cuerpos de la Policía Local. El artículo 52.1 LOFCS lo confirma indicando que Los Cuerpos de Policía Local son "Institutos armados de naturaleza civil, con estructura y organización jerarquizada". Por tanto, como institutos armados, se someten a un régimen especial regulado en la LOFCS, prevaleciendo siempre, en atención al principio de especialidad, sobre las determinaciones del EBEP, como corrobora la Sentencia del Tribunal Supremo de 7 de julio de 2007, al indicar que "ha de estarse primeramente a lo que establezca la propia ley orgánica".

En efecto, según lo dispuesto en el artículo 3.2 EBEP, "Los Cuerpos de Policía Local se rigen también por este Estatuto y por la legislación de las Comunidades Autónomas, excepto en lo establecido para ellos en la Ley Orgánica 2/1986, de 13 de marzo, de Fuerzas y Cuerpos de Seguridad".

Es más, a continuación el artículo 4.e) EBEP excluye a todos los Cuerpos y Fuerzas de Seguridad, salvo que la propia LOFCS disponga lo contrario. Quiere ello significar que el EBEP está excepcionando de forma expresa su aplicación a los Cuerpos y Fuerzas de Seguridad en general, y a las Policías Locales en particular, en todo lo que esté contemplado en la LOFGS.

En este sentido, el Consejo de Estado en Dictamen de 17 de junio de 2010, sobre la participación de representantes de las Comunidades Autónomas en los tribunales de selección de Entes Locales, determina que la LOCFS es de aplicación preferente a los preceptos del EBEP, y que esta norma no puede suponer una exclusión de aquélla en la fijación de los criterios de selección.

Por otra parte, siguiendo una interpretación histórica, la Ley 30/1984, de 2 de agosto, de Medidas para la Reforma de la Función Pública, excluía ya de su ámbito de aplicación (artículo 1) a los Cuerpos y Fuerza de Seguridad, por lo que resultaría indiferente que las bases impugnadas se hubieran dictado una vez entrado en vigor el EBEP. O lo que es lo mismo, que con una y otra norma, la conclusión es idéntica: que los Cuerpos de Policía Local se rigen por su legislación específica, quedando excluida la aplicación de la normativa básica sobre función pública, sin perjuicio de su supletoriedad. 
No podemos olvidar que la LOCFS se inscribe en el bloque de constitucionalidad, que fija el reparto competencial entre el Estado y las Comunidades Autónomas, por lo que como ya hemos indicado, la aplicación del EBEP supondría dejar sin efecto el contenido de la LOCFS, y por ende, las normas que las Comunidades Autónomas hubieran dictado en su desarrollo, concretamente $e x$ artículo 39 LOCFS.

De hecho, el EBEP constituye la legislación básica en materia de función pública, y su artículo 56 posee dicho carácter básico. Pero es que si bien la previsión contenida en dicho precepto exige reserva de ley para la fijación de un límite edad distinto de la jubilación forzosa, el propio EBEP en sus artículos 3.2 y 4.e) introduce una excepción a su aplicación como norma básica en función del ámbito subjetivo, respecto a los Cuerpos y Fuerzas de Seguridad, remitiéndose al régimen jurídico contenido en la LOCFS, pues el legislador ha querido regular especialmente una parte de la función pública.

Por tanto, no existe dicotomía entre el EBEP como ley básica, y la LOFCS como ley orgánica. Como viene estableciendo reiterada y pacífica jurisprudencia del Tribunal Constitucional, las relaciones entre ambos tipos de leyes no es jerárquica, sino de competencia, motivo por el que el EBEP se remite a la LOFGS, así como porque se trata de una materia reservada a ley orgánica que, como tal, no puede ser modificada por una ley ordinaria.

El hecho de que el EBEP sea una ley básica en materia de función pública no empece que, con base a un principio de especialidad, la LOFCS tenga su propia regulación, debido a las características que se predican de este colectivo de funcionarios, que cuentan con una serie de importantes peculiaridades y limitaciones en su régimen jurídico ${ }^{1}$.

${ }^{1}$ Así lo expone la Sentencia del Tribunal Supremo, Sección 7 $7^{\mathrm{a}}$, de 13 de julio de 2007, que en Recurso en interés de Ley, referido a la aplicación principal y preferente de la LOFCS sobre la normativa básica, indica que:

"La técnica de la ley básica esta prevista en la Constitución Española para regular el reparto competencial legislativo entre el Estado y las Comunidades Autónomas, sin que la existencia de una ley básica impida al legislador estatal regular de forma distinta una determinada materia. En este sentido son numerosas las leyes sectoriales que se apartan de la básica -por citar una, la Ley General Tributaria, en relación con la ley 30/1992, de 26 de noviembre, que regula determinadas instituciones de forma distinta". 
En contra de lo que interpreta la Sentencia, no cabe duda que las disposiciones de la LOFGS, son de directa aplicación en cuanto a los mecanismos de coordinación de policías locales, y más concretamente de su peculiar régimen estatutario, lo que lleva a sostener la aplicación directa de la normativa autonómica para fijar los criterios de selección, según el mandato del artículo 39 LOCFS, con base a los principios de competencia (ex artículo 148.1.22 $2^{\mathrm{a}}$ de la Constitución), y especialidad (artículos 104.2 CE, 3.2 EBEP y 39 LOFCS), pues como advierte el Tribunal Constitucional, "la inclusión de una competencia genérica debe ceder ante la competencia específica" (STC 192/2000, de 13 de julio, con referencia a las SSTC 75/1982 y 877/1989).

De este modo, la Administración Autonómica Andaluza ha desplegado las competencias que le confiere la LOGFS con la aprobación de la Ley 13/2001, de 11 de diciembre, de Coordinación de las Policías Locales y el Decreto 201/2003, que en su artículo 18 regula la edad máxima para el acceso al cuerpo de policías locales, siendo perfectamente legítimo desde el punto de vista de rango normativo, que esta previsión se contenga en una disposición de carácter general, pues la regulación del régimen estatutario de las policías locales no está sometida al EBEP, sino a la LOFCS y a las normas de las Comunidades Autónomas, sin que se exija rango de Ley en lo que respecta a los requisitos de acceso al cuerpo, entre los que se incluye la edad ${ }^{2}$.

En adveración de todo lo antedicho, el artículo 7.b) del Reglamento de los procesos selectivos y de formación en el cuerpo nacional de policía, aprobado por Real Decreto 614/1995, de 21 de abril, fija como criterio para participar en las pruebas selectivas "Tener dieciocho años de edad y no haber cumplido los treinta". Téngase en cuenta que de conformidad con lo dispuesto en su artículo 1, dicha norma se dicta en desarrollo de la LOFCS, y lo que es más importante, posee rango reglamentario, sin que hasta el momento se haya discutido su legalidad, pues la LOCFS no exige reserva de ley para delimitar los requisitos de acceso de los aspirantes.

${ }^{2}$ El ya mentado Dictamen del Consejo de Estado de 17 de junio de 2010, señala que las Leyes de Coordinación de las Policías Locales, sirven de apoyo a las normas reglamentarias que fijan los criterios de selección. Respecto al rango normativo que debe revestir dichos criterios para los Cuerpos de Policía Local, el mentado Dictamen establece lo siguiente:

"Si bien esta competencia se ha ejercitado en ocasiones mediante Ley (...) en otros muchos casos es una norma de rango reglamentario la que precisa esta composición. Así lo han hecho varias Comunidades Autónomas en normas entre las que cabe citar el Decreto 201/2003, de 8 de julio, de ingreso, promoción interna, movilidad y formación de los Cuerpos de Policía Local de Andalucía...". 
A mayor abundamiento, recientemente ha sido publicado el Reglamento de ingreso y promoción y de ordenación de la enseñanza de formación en las Fuerzas Armadas, aprobado por Real Decreto 35/2010, de 15 de enero, que regula en su artículo 16 los requisitos específicos de edad máxima, que oscilan entre los 20 y 37 años, los cuales en ningún caso podrán ser superados para participar en los procesos de selección, debiendo tener en cuenta que el Consejo de Estado, en Dictamen 1782/2009, no hace objeción alguna al respecto.

Por todo ello y en definitiva, el régimen jurídico de los Cuerpos de Policía Local, dada su particular naturaleza, ha de quedar excluido de la regulación del EBEP por expresa previsión de sus artículos 3.2 y 4.e), conteniéndose en la LOCFS, por lo que la reserva de Ley establecida en el artículo 56.1.c) EBEP, no resulta aplicable respecto de los Cuerpos de Policía Local, siendo competentes las Comunidades Autónomas para fijar los criterios de selección de dichos Cuerpos de Policía Local, mediante normas con rango reglamentario, en aplicación del artículo 39 LOCFS.

Sentado lo anterior, y descendiendo al caso concreto, vemos que en la Sentencia de la Sala, se defiende sin embargo, que no existe precepto legal que exceptúe de aplicación la previsión de reserva de Ley contenida en el artículo 56.1.c) EBEP, dada la interpretación - a nuestro respetuoso juicio errónea-, que mantiene la Sala sobre el régimen jurídico aplicable a los Cuerpos de la Policía Local.

Entendemos no obstante que debe partirse de lo dispuesto en el artículo 39 LOFCS, el cual establece que corresponde a las Comunidades Autónomas coordinar la actuación de las policías locales, fijando "los criterios de selección, formación, promoción y movilidad de las Policías Locales", lo que se materializa en el ejercicio de potestades normativas.

A partir de aquí, no cabe duda de que la doctrina que postula la Sentencia de la Sala en apelación, es errónea y gravemente dañosa para el interés general, desde el momento en que no considera la edad como un "criterio de selección", cuando bien es sabido que la edad es, cualitativamente, un requisito esencial indiscutible para el acceso a la función pública, formando parte, por tanto, de los criterios de selección.

Resulta incoherente, pues, que la LOFCS deba referirse a la edad de acceso a los Cuerpos de Policía Local, toda vez que ésta constituye un criterio de selección. De admitirse la tesis de la Sentencia, todo requisito de acceso a la 
función pública que no estuviera contemplado de manera expresa en la LOCFS (tener más de dieciocho años, ser español, etc.), conllevaría la aplicación del EBEP, lo que equivaldría a dejar sin efecto el contenido del artículo 39 LOCFS.

Esta exégesis es contraria a lo dispuesto en el artículo 3.1 del Código Civil, al no haber interpretado el citado precepto conforme al sentido propio de sus palabras, ni a su espíritu y finalidad. Desde una perspectiva de lege ferenda, es evidente que las normas no tienen que integrar un contenido tan exhaustivo como el propuesto por la Sentencia de la Sala en apelación, bastando con que se infiera del mismo, acudiendo a otros preceptos del ordenamiento jurídico con base al principio de plenitud, en los términos antes indicados.

Pero es que además, respecto a la supuesta falta de justificación por las bases del límite de edad, la exigencia del mismo se encuentra implícita en la naturaleza del cuerpo al que se aspira ${ }^{3}$. Pues bien, en este orden de cosas, a efectos de la trasposición de la Directiva 2000/78 CE del Consejo, de 27 de diciembre de 2000, relativa al establecimiento de un marco general para la igualdad de trato en el empleo y la ocupación, se dictó la Ley 62/2003, de 30 de diciembre, de medidas fiscales, administrativas y del orden social, indicando en su artículo 34 que "Las diferencias de trato basadas en una característica relacionada con cualquiera de las causas a que se refiere el párrafo anterior -origen racial o étnico, religión o convicciones, discapacidad, edad u orientación se-

${ }^{3}$ Por todas, la STC 75/1983, de 17 de agosto, concluye lo siguiente:

"Es claro que para el cumplimiento de dichas funciones la Administración está obligada a velar por que los aspirantes reúnan unas condiciones físicas y psíquicas acordes al contenido y relevancia de las funciones atribuidas al puesto de trabajo y esas condiciones físicas comprenden no sólo la exigencia de una determinada aptitud física sino también de una determinada constitución física, siendo llano que la determinación de dichas circunstancias físicas (altura o edad) no se realiza con acepción de personas, es objetiva y general, no arbitraria.

Tal es la importancia del requisito de la edad para el ingreso en el CNP que el limite de 30 años enjuiciado se justifica no solo en la potestad del Estado de seleccionar al personal que considere idóneo para el cometido de las funciones a encomendarle, sino incluso en el que esta selección concreta tiene por fin el que por el Estado se garantice la seguridad ciudadana, lo cual implica la realización de cometidos que requieren en todo funcionario policial un buen estado físico general, lo que se garantiza de modo objetivo no solo con la realización de pruebas fisicas sino igualmente con el establecimiento de un limite de edad para el acceso a la función policial. Y si la edad y las condiciones fisicas son elementos esenciales para la función policial, por su eficacia, operatividad, riesgo y penosidad, serán estas mismas circunstancias las que justifiquen la limitación de edad por ingreso, y por ello la hagan razonable y constitucionalmente admisible, sin que de ella pueda colegirse arbitrariedad o discriminación alguna". 
xual- no supondrán discriminación cuando, debido a la naturaleza de la actividad profesional concreta de que se trate o al contexto en que se lleve a cabo, dicha característica constituya un requisito profesional esencial y determinante, siempre que el objetivo sea legítimo y el requisito proporcionado".

Así, la exposición de motivos de la LOCFS declara que "las condiciones físicas son especialmente determinantes de la eficacia en el ejercicio de la profesión policial", lo que ha de ponerse en relación con la exposición de motivos de la Ley 26/1994, de 29 de septiembre, por la que se regula la situación de segunda actividad en el cuerpo nacional de policía, cuando señala que "las funciones que, por mandato constitucional, la Ley Orgánica 2/1986, de 13 de marzo, de Fuerzas y Cuerpos de Seguridad, atribuye a los funcionarios del Cuerpo Nacional de Policía, son eminentemente operativas y en ocasiones arriesgadas y penosas, lo que requiere determinadas aptitudes psicofísicas en aquellos, que naturalmente se van perdiendo con la edad o por determinadas circunstancias".

La fijación de un límite de edad no tiene, pues, carácter discriminatorio, sino que está en función de las características propias del cuerpo al que se aspira, y en el caso de las Policías Locales es necesaria no sólo una capacidad física concreta, sino que además, ésta se mantenga durante un periodo de tiempo relativamente largo, para garantizar la eficacia del cuerpo policial en su conjunto, y evitar la acumulación de funcionarios destinados a segunda actividad, con el consiguiente perjuicio al Cuerpo, y por ende, al servicio público.

En atención a ello, el límite de la edad parte de una doble necesidad: la de garantizar unas condiciones físicas apropiadas a la naturaleza de las funciones encomendadas, y de mantenerlas a lo largo de un periodo de tiempo suficiente. No es un problema de hallarse o no en las adecuadas condiciones en el momento del ingreso, lo que es desde luego exigible, y a ello responden las pruebas físicas y otras exigidas en la convocatoria, sino la garantía de estabilidad de la plantilla ingresada en sus mejores condiciones y a lo largo de un periodo suficiente de tiempo, porque indudablemente ello contribuye al logro de la necesaria eficacia del cuerpo policial en su conjunto.

No podemos concluir sin mencionar la Sentencia de la Gran Sala del Tribunal de Justicia de las Comunidades Europeas de 12 de enero de 2010, atinente al cuerpo de bomberos, que ha venido a confirmar todo lo expuesto, justificando la necesidad de fijar un límite de edad, dado que la edad 
máxima de contratación impuesta tiene el objetivo de garantizar que los funcionarios puedan cumplir las misiones que exigen una capacidad física particularmente elevada durante un período de tiempo relativamente largo de su carrera.

Consideramos como valoración final, que los fundamentos de la Sentencia no se ajustan a una interpretación acorde con el principio de especialidad normativa, el principio rationae materie, al impedir la aplicación de las normas de las Comunidades Autónomas sobre la materia por imperativo del artículo 39 LOGFS, y el principio de seguridad jurídica. 